\title{
Priorities in occupational health research: a Delphi study in The Netherlands
}

\author{
Allard J van der Beek, Monique H W Frings-Dresen, Frank J H van Dijk, \\ Irene L D Houtman
}

\begin{abstract}
Objectives-To achieve a coherent programme of topics for research in occupational health and safety, with well founded priorities and to relate them to perceived gaps and needs in The Netherlands. Methods-In the first phase of the study 33 key informants were interviewed. In the second phase questionnaires were sent to 150 Dutch experts (including the key informants). Four groups were recruited, originating from: occupational health and safety services; scientific research institutes; governmental and other administrative bodies; and companies. Using the Delphi technique, the experts were asked to prioritise several topics, which were placed under different headings. In the third phase five workshops were organised to elaborate on the highly prioritised topics.
\end{abstract}

Results-The response rates were $86 \%$ for the first and $81 \%$ for the second questionnaire. In the second round consistency was reached and consensus proved to be satisfactory, so that the Delphi process was stopped. There were surprisingly few differences in opinion between the four groups. The most important heading was "design/implementation/evaluation of measures", in which the topic cost-benefit analysis of measures had the highest score. "Assessment of relations between exposure and effect" was the second most important heading. Under this heading, topics on work stress were generally judged to be more important than topics on musculoskeletal disorders, which in turn had higher scores than topics on safety and biological, chemical, and physical hazards. The headings "occupational rehabilitation/sociomedical guidance" and "occupational health care occupational health services" had about the same priority, closely following the heading "assessment of relations between exposure and effect".

Conclusions-The general agreement on priorities should provide a sufficiently broad basis for decision makers to initiate a long term programme for occupational health research and development in The Netherlands.

(Occup Environ Med 1997;54:504-510)
Keywords: priorities; occupational health research; Delphi technique

More than 10 years ago it was concluded in a European Community workshop that one of the main constraints in occupational health research was the deficiency in the identification of suitable research topics and priorities. Since then, research priorities have been established-for instance, in the United Kingdom in a study by Harrington ${ }^{2}$. Setting of priorities is more likely to be carried out by government institutions in the United States and the Scandinavian countries. ${ }^{3}$ These countries' National Institutes of Occupational (Safety and) Health often carry out research programming and planning. Moreover, a considerable part of the scientific research and the development of methods, techniques, and instruments is done or initiated by these institutes. In contrast, in The Netherlands occupational health research and development is fragmented over many different universities and institutes, whereas national infrastructure to stimulate, coordinate, and programme is limited. These tasks used to be partially fulfilled by the Ministry of Social Affairs and Employment, assisted by an independent Advisory Group for Safety and Occupational Health Research. However, recently the Ministry has relinquished such responsibilities under central government's gradual opting out process, which has resulted, among other things, in the abolition of the Advisory Group. Due to this hiatus the Council for Health Research has become more committed to the programming and priority setting for research in the sphere of work and health. The Council is an advisory body that offers different Ministers support on formulation of policies on health research, on which the government spends around one billion Dutch guilders each year. Its function does not include actual financing and control of research programmes.

In general, there is a need for knowledge, instruments, and transfer of knowledge and skills that contribute optimally to preventing workers from developing or continuing to have health problems on the one hand, and enabling people who have (had) health complaints to return to their jobs on the other hand. Much is still unknown and many methods, techniques, and instruments have to be developed in the wide field of occupational health and safety. For instance, for several work related diseases the relevant risk factors are insufficiently identified and there seems to be a lack of knowledge 


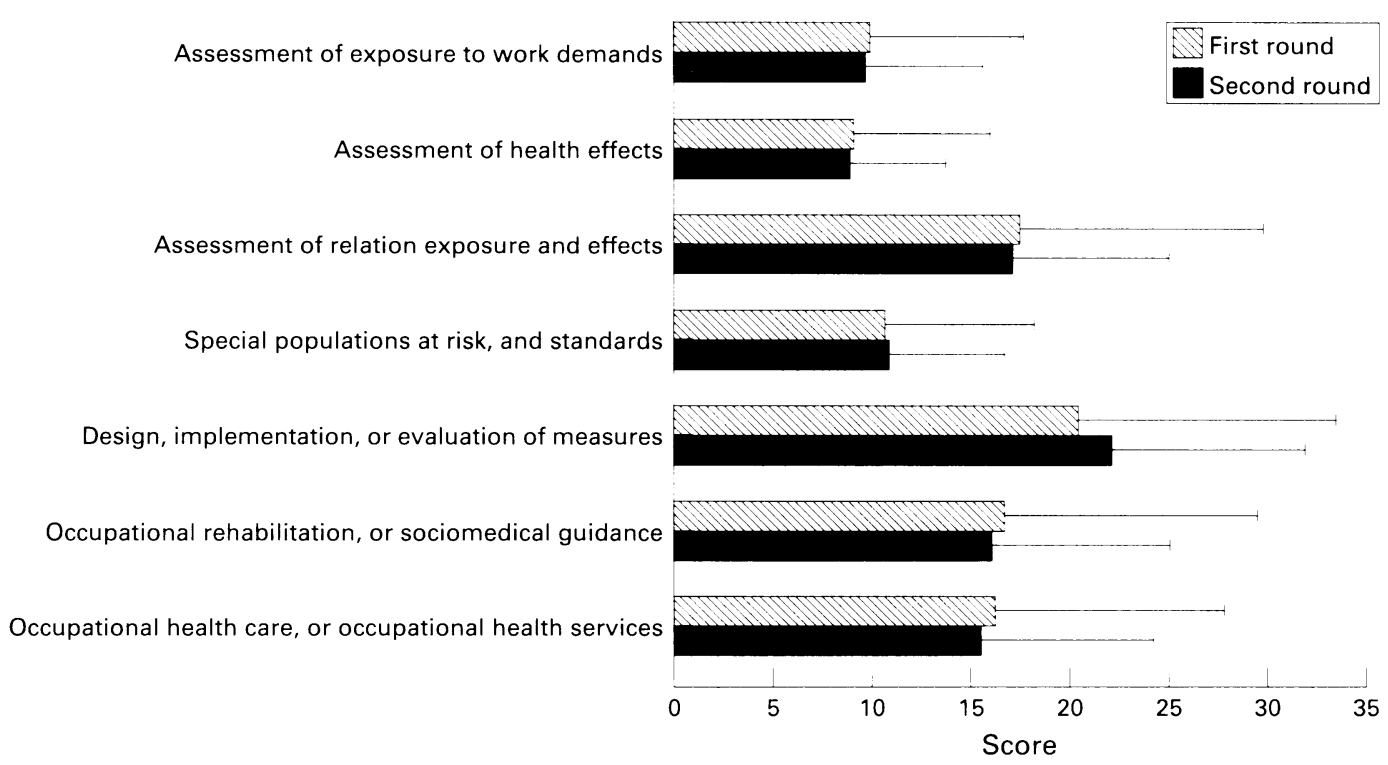

Figure 1 Mean (SD) of the scores (points) for the headings in the questionnaire's first and second rounds.

about the effectiveness and efficiency of occupational health care. Funds are not infinite, so that choices have to be made. This stresses the importance of identifying priorities in occupational health research and development. However, it is unclear which specific areas deserve emphasis, not to mention the corresponding research questions. To enable the Council for Health Research to advise on future medium and long term research policies, a programming study was carried out. The study's aim was to find a coherent programme of topics for research and development in occupational health, with well founded priorities that relate to perceived gaps and needs.

\section{Methods}

This study was carried out in three phases. In the first phase key informants were interviewed. For each of five themes six key informants were selected, three scientific researchers (in all, nine from universities and six from research institutes) and three from occupational health and safety services (in all, 10 from independent consulting services and five from departments within large companies). The five themes were: (a) work stress, (b) musculoskeletal disorders, (c) safety and biological, chemical, and physical hazards, (d) occupational rehabilitation/sociomedical guidance, and (e) occupational health care/occupational health services. Furthermore, to accomplish broad national support three senior governmental policy makers were invited to participate. These $33 \mathrm{key}$ informants were asked to indicate topics that they themselves considered of great importance for research needs and knowledge, development of methods and techniques, or transfer of knowledge and skills. The transfer of knowledge and skills implies the communication of study results from universities and research institutes to occupational health services or companies. Subsequently, the key informants were questioned on each of these topics about their strengths in The Netherlands, possible bottlenecks in scope and quality, current gaps, and whether or not there was an actual social need for those gaps to be filled.

In the second phase the topics that were brought up in the interviews were prioritised in questionnaires through the Delphi technique. This technique enables mutually anonymous experts to reach consensus through the use of successive questionnaires. ${ }^{5}$ By means of these iterations controlled feedback is given on the group's collective opinion in the preceding Delphi round, which allows the experts to reconsider their views. In the present study the topics were divided among seven headings (fig 1). In each of these headings 100 points had to be apportioned among the topics specified, ranging from the minimum of zero to a maximum of 50 points per topic. Subsequently, the number of points given to a topic could be subdivided into scientific research to gain knowledge, and research and development to substantiate activities of companies and occupational health services. At the end of the questionnaire the same apportioning of 100 points (except for the subdivision) was used to prioritise the headings compared with each other. In the first round, space was provided for the respondents to add topics that had not been included. In the second round, feedback was given for each topic and each heading by the mean and interquartile range of the score in the first round.

The first questionnaire was sent to 105 Dutch experts that included the key informants. In this round three groups were involved, originating from: (a) occupational health and safety services, $(b)$ scientific research institutes and universities, and $(c)$ governmental and other administrative bodies (table). The experts were selected on the basis of their professional experience to provide roughly equal representation of the five original themes. After two weeks non-respondents of the first round were sent a reminder. In the second round another 45 people were added to the group of experts, about half of whom were personnel 
Table 1 Response and background of the experts who were invited to participate in the first and second round of the Delphi questionnaire

\begin{tabular}{|c|c|c|c|c|c|}
\hline \multirow[b]{2}{*}{ Background of the experts } & \multirow{2}{*}{$\begin{array}{l}\text { Invited experts } \\
n\end{array}$} & \multicolumn{2}{|c|}{ Response 1st round } & \multicolumn{2}{|c|}{ Response 2 nd round } \\
\hline & & $n$ & $(\%)$ & $n$ & $(\%$ of $1 s t)$ \\
\hline Occupational health services & 35 & 34 & (97) & 32 & (94) \\
\hline Scientific research institutes & 35 & 33 & (94) & 33 & $(100)$ \\
\hline \multicolumn{6}{|l|}{ Governmental and other } \\
\hline administrative bodies & 35 & 23 & $(66)$ & 18 & $(78)$ \\
\hline Companies * & 45 & - & $(-)$ & 27 & $(60)$ \\
\hline
\end{tabular}

* Experts from companies took part only in the 2nd round.

managers responsible for health and safety and about half employees or employee representatives actively involved in health and safety matters of their company. The non-respondents of the second round were sent a reminder after one month.

Differences in priorities between the four groups were tested by one way analysis of variance (ANOVA) and additional analyses were carried out with Student's $t$ test. Differences were accepted as significant at $P<0.05$.

In the third phase a conference was organised that consisted of five theme oriented workshops to elaborate on the prioritised topics. The main objective was to formulate concrete research questions and corresponding projects for the six topics with highest priority in each theme. Furthermore, the feasibility and desirability of the projects were evaluated, which could result in reordered priorities. It was attempted to reach agreement.

\section{Results}

In the table the response rates in the first and second round are shown for the four different groups of experts. The total response rate was $86 \%$ in the first round and $81 \%$ in the second round, in which feedback of the results of the first questionnaire was given. In general, the response rates in the second round were similar to those in the first: high for occupational health and safety services and scientific research institutes (around 95\%), and less satisfactory for the governmental and administrative bodies. The response rate in the first round of these experts in policy making positions only improved to $66 \%$ after the nonrespondents had been contacted by telephone, and in the second round only 18 completed questionnaires were returned by this group. The group from the companies took part only in the second round; $27(60 \%)$ of the 45 canvassed personnel managers and (representatives of) employees responded.

Figure 1 shows the mean (SD) of the heading scores for all respondents in the first and second round. There were hardly any differences between the rounds, indicating that consistency was reached. The decrement in variability indicated an increase in consensus among the experts, although the SDs were still wide in the second round. However, agreement between the two rounds and between experts was considered to be sufficiently advanced and the Delphi process was stopped.

The highest priority was given to the heading "design/implementation/evaluation of measures". "Assessment of relations between expo- sure and effect" was the second most important heading and was rated higher than "assessment of exposure to work demands" and "assessment of health effects" separately. The headings "occupational rehabilitation/sociomedical guidance" and "occupational health care and occupational health services" had about the same priority.

For the heading "design/implementation/ evaluation of measures", the highest priority was given to the topic cost-benefit analysis of measures (fig 2). In the workshop it was stressed that studies for this topic should be performed at the level of both macroeconomics and companies. Another highly prioritised topic was design of solutions by workers for their own work situation, which should mainly be directed at the development of participatory methods to be used by companies and occupational health services. For the third most important topic, methods have to be developed that can serve as general guidance for advisers to implement preventive measures. Studies are needed about how best to organise the implementation process-that is, started up, managed, and completed. The possible problems with the cooperation of different participants in the implementation process and the corresponding solutions should be included in this general guidance.

Under the heading "assessment of relations between exposure and effect", most of the topics related to the theme of work stress were judged as being more important than topics on the theme of musculoskeletal disorders. Topics on musculoskeletal disorders had higher scores in general than topics of the theme of safety and biological/chemical/physical hazards. Figure 3 shows the two topics with the highest score of each of these three themes. For the relation between work pressure and business effects - such as productivity-as well as between perception of stress risks and objective health effects-such as registered sickness absencemodels should be developed in which perception is placed between objective causes and effects. It should be tested whether or not perception mediates in the causal chain. Within the theme musculoskeletal disorders, identification of risk factors for complaints in the neck, shoulders, and arms associated with repetitive handling had the highest priority. For the relation between working postures and musculoskeletal complaints it was agreed that risk factors were more or less known and that insight should be gained into their relative contributions and dose-response curves. For the relation between indoor environment and accompanying subjective perception, tools should be developed to evaluate and improve work situations systematically. To gain knowledge on the relation between exposure to toxic hazards and reproductive effects early indicators of fertility problems are needed, at first for scientific research.

Figure 4 provides prioritised topics for "occupational rehabilitation/sociomedical guidance". Firstly, to explore beneficial and impeding factors for return to work, longitudinal studies are needed, because little is known about the course of sickness absence at the 


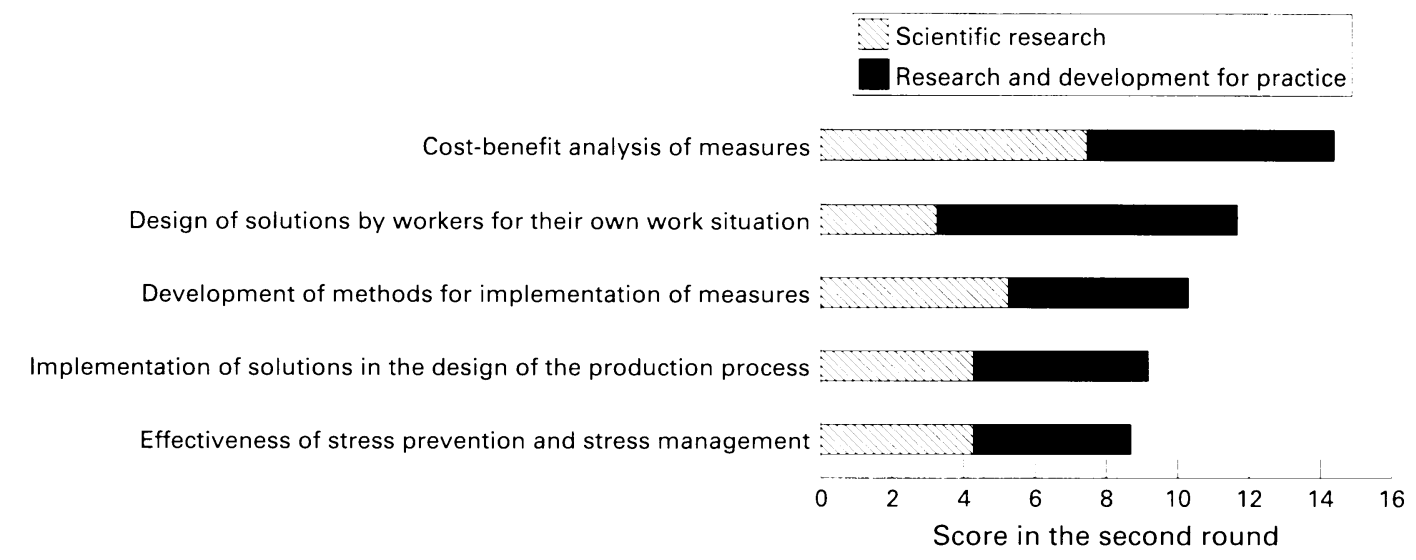

Figure 2 Mean scores (points) for the main topics placed under the heading "design/implementation/evaluation of measures", divided into scientific research to gain knowledge, and research and development to substantiate activities of companies and occupational health services.

individual level. Secondly, research and development to substantiate the activities of vocational counsellors was considered of importance to organisationally gear all those involved in rehabilitation to one another. Experiences from abroad should be used for the introduction of this type of case management in The Netherlands.

Figure 5 shows the topics with the highest score under the heading "occupational health care/occupational health services". Costs and benefits of occupational health care should be well defined and in future research benefits at the company level have to be increasingly assessed. For the second most important topic occupational health care in small and medium sized companies practical instruments and methods that closely fit these companies' way of thinking and operational management have to be developed and evaluated.

Apart from the response rates (relatively low for policy makers from governmental and administrative bodies and for personnel managers and employees from companies) there were surprisingly few differences between the four groups. In the second round the only heading score that differed significantly was "assessment of relations between exposure and effect". This heading received significantly less points from the policy makers than from the other groups. There was only one significant difference between the groups in topics given in the figures-that is, the relation between perception of stress risks and objective health effects-such as registered sickness absence. Scientific researchers considered this topic of less importance than the other groups did (marginally significant for the group of policy makers and significant for both other groups). The less highly prioritised topics (those not presented in one of the figures) also showed a remarkable agreement in scores, although there were some exceptions. Most of the time these exceptions were differences of opinion between the group that consisted of personnel managers, employees, and employee representatives and one or more of the other groups. For instance, the rating of the topic involvement of management under the heading "occupational rehabilitation/sociomedical guidance" was significantly higher for the group from companies than for the research group. Under the same heading, the topic contact with workers after reporting sick received significantly more points from the group from companies than from the other groups, which was also the case

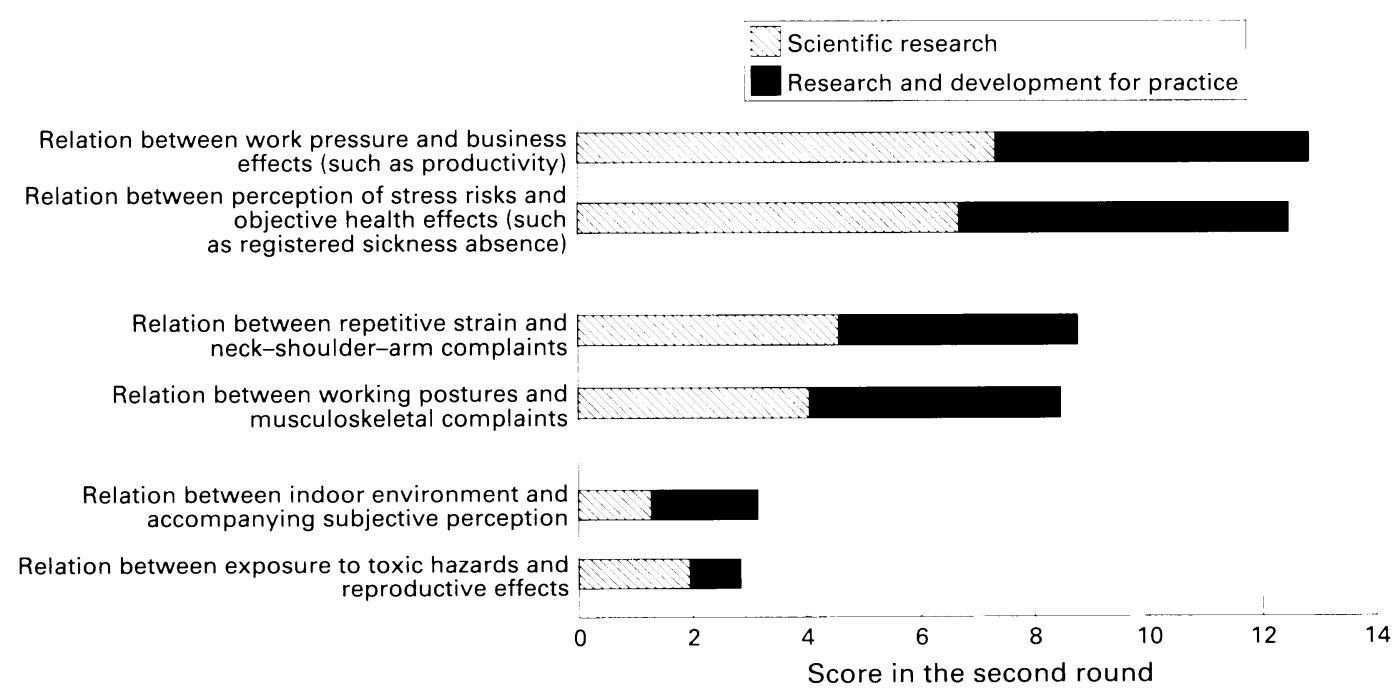

Figure 3 Mean scores (points) for the main topics placed under the heading "assessment of relations between exposure and effect", divided into scientific research to gain knowledge, and research and development to substantiate activities of companies and occupational health services. 


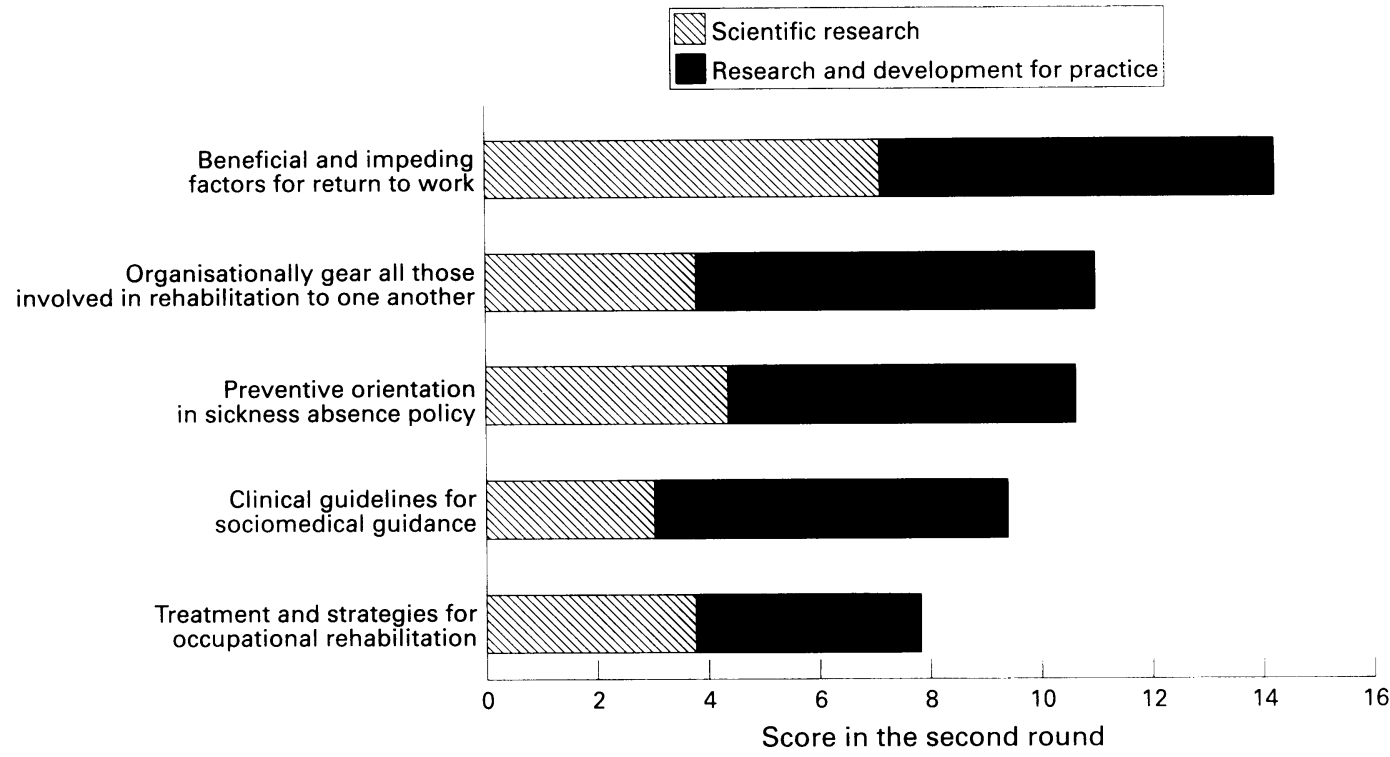

Figure 4 Mean scores (points) for the main topics placed under the heading "occupational rehabilitation/sociomedical guidance", divided into scientific research to gain knowledge, and research and development to substantiate activities of companies and occupational health services.

for the topics effectiveness of annual programme for occupational health and safety and reference to the position of other companies (bench marking) under the heading "occupational health care/ occupational health services". However, under the heading "occupational health care/ occupational health services" effectiveness of counselling received significantly more points from the group from occupational health services than from the other three groups.

\section{Discussion}

The findings of this study were principally obtained from: (a) the interviews with key informants, $(b)$ the setting of priorities in topics for research with Delphi questionnaires, and (c) the five workshops organised at the end of the Delphi process. This means that the results were solely based on opinions of experts, who have their own interests (in more than one meaning of the word). Therefore, the aim was to accomplish not only heterogeneity of experts, but also equal representation of different fields (five themes) and professional duties (four groups). This goal was only partly achieved, due to the rather disappointing response rates for the group of policy makers from governmental and other administrative bodies and for the group from companies. This was anticipated from companies, but not from governmental and other administrative bodies. However, it is known who has responded and who has not, which can shed some light on differences between responders and nonresponders in these groups. In the group of policy makers the professional background between the responders and non-responders did not differ, so that roughly equal representation of the five themes is provided by the responders of this group. The group from companies showed no significant difference in response rate between personnel managers and

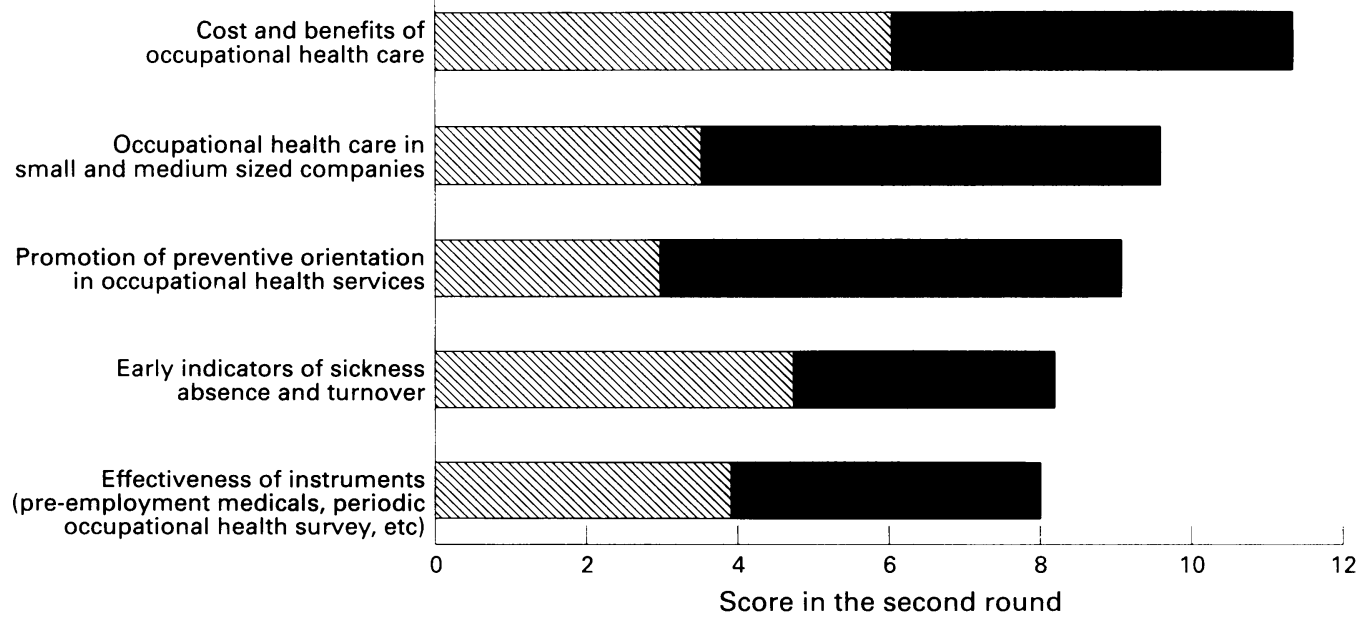

Figure 5 Mean scores (points) for the main topics placed under the heading occupational health care and occupational health services, divided into scientific research to gain knowledge, and research and development to substantiate activities of companies and occupational health services. 
(representatives of) employees, as a result of which they were about equally represented in the population. These comparisons present some evidence that substantial selection bias did not occur. Furthermore, there were hardly any differences between the scores of the four groups, so that the underrepresentation of the policy makers had probably no serious consequences for the validity of the results.

The Delphi technique has been used before in The Netherlands in a forecasting study, in which experts were asked to give their opinion on future developments in the field of work and health for seven different scenarios. ${ }^{6}$ Apart from this scenario study, it has been used successfully in the assessment of research priorities in the United Kingdom. ${ }^{2}$ In general, the Delphi technique has three characteristics that distinguish it from face to face group meetings: $(a)$ anonymity, $(b)$ iteration with controlled feedback, and $(c)$ statistical group response. ${ }^{7}$ This has many advantages, but limitations as well. For instance, the striving for consensus results in useful extreme views being suppressed and Delphi lacks the stimulation of face to face group interaction. These limitations were partly overcome by obtaining the initial information through interviews (usually through a completely unstructured questionnaire in the first Delphi round) and especially by organising workshops to elaborate collectively on the prioritised topics.

In a comparable study of British medical opinion on research priorities ${ }^{2}$ broad agreement was found between representatives of academic occupational health and occupational physicians working in industry. A further survey of United Kingdom personnel managers showed that they generally agreed with these priorities, ${ }^{8}$ although stress received a higher ranking. This consensus was confirmed for the four groups canvassed in the present study. Beforehand considerable differences were expected among groups, analogous to the differences in opinion of managers, employee representatives, and occupational physicians with respect to functions that should be provided by occupational health services. ${ }^{9}$ It can be concluded that there was less disagreement than expected on priority areas and topics in occupational research and development.

A comparison between priorities in the United Kingdom and The Netherlands is hampered by major differences in topic headings between both studies, but some similarities were noted. For instance, in both studies high priority was given to a work stress topic for which the development of objective measures of exposure and health effects was needed and to a topic relating to the identification of aetiological and predisposing factors leading to upper limb disorders related to work.

The area with highest priority for special attention in future occupational health research proved to be the design, implementation, and evaluation of control measures. Apparently, the collective view was that the time has come to improve work situations by preventive measures and control solutions. This was in agreement with some of the most important recommendations in a document recently developed by the World Health Organisation (WHO) Collaborating Centres in Occupational Health. ${ }^{10}$ Furthermore, this area entirely corresponds with one of the 21 areas for special emphasis that have been chosen by the United States' National Institute for Occupational Safety and Health (NIOSH), ${ }^{11}$ the area of intervention effectiveness research. In recent years it has been widely recognised that methods for analysing and designing preventive measures should be developed and that information on successes and failures should be shared. ${ }^{12}$ The WHO has stimulated this transfer of knowledge with the formation of a Working Group on Prevention and Control Exchange (PACE).$^{12}$

The second most important heading was "assessment of relations between exposure and effect". It was not surprising that in this epidemiological area topics on work stress had the highest scores in general, because in The Netherlands the prevalence of exposure to psychosocial work demands and the corresponding health effects have increased during the past decades and will probably increase even further in the near future. ${ }^{4613}$ In particular, scientific research is needed to gain knowledge of the relation between objective exposure, subjective perception, and business aspectssuch as productivity and registered sickness absence. There was balance between the subdivision of the musculoskeletal topics into scientific research to gain knowledge and practically oriented research and development. In particular in the workshop the practically oriented research and development was found to be more relevant for the topic related to the indoor environment and accompanying subjective perception. The high priority for topics on complaints of the upper limb and indoor environment accords with the recent National Institute for Occupational Safety and Health (NIOSH) research agenda. ${ }^{11}$ The relatively low scores for topics of the theme safety and biological/chemical/physical hazards reflected the general opinion. Even safety experts, occupational hygienists, and toxicologists did not give many points to their own topics, although they gave more than the rest of the experts who were invited to participate in the study.

In "occupational rehabilitation/sociomedical guidance" as well as "occupational health care/ occupational health services" the emphasis was generally laid on research and development to substantiate activities of companies and occupational health services. The high priority for costs and benefits of occupational health care can be explained by the transition from a supplier dominated market to a situation in which clients are more influential. ${ }^{14}$ Due to recent changes in Dutch legislation ${ }^{13}$ there should be urgent consideration of the topics beneficial and impeding factors for return to work as well as occupational health care in small and medium sized companies which has also been perceived internationally as being needed. ${ }^{10}$ It was remarkable that in both areas a topic on prevention showed up, apart from topics related to efficiency, clinical guidelines, costs 
and benefits, and effectiveness. Apparently, the experts thought that the preventive aproach to occupational health was in danger of being overlooked. Furthermore, it is noteworthy that the present study's topics related to research on economics, effectiveness, and prevention in occupational health are generally similar to issues in the NIOSH priority area of health services research. ${ }^{11}$

In conclusion, surprisingly broad agreement was reached on the principal priorities in occupational health research. We think that decision makers from government, employers' organisations, and trade unions are the final key to a long term programme for occupational health research and development in The Netherlands. Parts of the programme that resulted from this study can be included in adjacent research programmes. For instance, the Foundation for Quality Improvement in Occupational Health Care (SKB) has recently drawn up a research and development programme for the next few years and has relied heavily on results from the area of "occupational health care/occupational health services" from this study. ${ }^{15}$ On the other hand, although it is internationally recognised that it is useful to identify areas where research is perceived to be needed, it should be mentioned that often useful and important advances in knowledge come from studies that are inspired by the researcher's own interest or his or her recognition of an unusual or even unique opportunity for an investigation.

We thank Professor A Struyvenberg and KSM Jurgens (both Council for Health Research), AGJ de Koningh (Shell Occupational Health Service), and RJ Fortuin (SKB) for their important contributions to this study and $\mathrm{Dr} L$ Punnett (University of Massachusetts Lowell) for her valuable comments on the manuscript.
1 Vanhoorne M, Harrington JM, Parmeggiani L, Hunter W, Baert A, Vuylsteek $K$. Constraints in the development of occupational health research and its application: report on a workshop. Int Arch Occup Environ Health 1985;55:33749.

2 Harrington JM. Research priorities in occupational medicine: a survey of United Kingdom medical opinion by the Delphi technique. Occup Environ Med 1994;51:289-94.

3 Rantanen J. Priority setting and evaluation as tools for planning research strategy. Scand $₹$ Work Environ Health ning research strategy.

4 Ministerie van Sociale Zaken en Werkgelegenheid (SZW) Integraal Beleidsplan Arbeidsomstandigheden (integral policy plan on working conditions). The Hague: SZW, 1991.

5 Linstone HA, Turoff M, eds. The Delphi method: techniques and applications. Reading, Massachusetts: Addison-Wesley Publishing Company, 1975.

6 Steering Committee on Future Health Scenarios. Work and health: risk groups and trends. Dordrecht: Kluwer Academic Publishers, 1994.

7 Martino JP. Technological forecasting for decision making. 2nd ed. New York: North-Holland, 1983.

8 Harrington JM, Calvert IA. Research priorities in occupational medicine: a survey of United Kingdom personne tional medicine: a survey of United Kingdom

9 Williams N, Sobti A, Aw T-C. Comparison of perceived occupational health needs among managers, employee representatives, and occupational physicians. Occup Med 1994;44:205-8.

10 World Health Organisation. Global strategy on occupational health for all. The way to health at work. Geneva: WHO, 1995 (Publ No WHO/OCH/95 1)

11 National Institute for Occupational Safety and Health (NIOSH). National occupational research agenda. Washington: NIOSH, 1996 (DHHS (NIOSH) Publ No 96-115).

12 Swuste P, Corn M, Goelzer B. Hazard prevention and control in the work environment: report of a WHO meeting. International fournal of Occupational Medicine and Environ mental Health 1995;8:7-10.

13 Van Dijk FJH, Prins R. Occupational health care and work incapacity: recent developments in The Netherlands. Occup Med 1995;45:159-66.

14 Plomp HN, Berenbroek B. Bedrijfsgezondheidsdiensten op weg naar een meer bedrijfsmatig regime: concepten voor effectieve, marktafhankelijke professionele organisaties (occupational health services on their way to a mane business like regime: concepts for effective, market-dependen professional organizations). Tijdschrift voor Sociale Gezondheidszong 1994;72:398-406.

15 Fortuin RJ. Voorstel Meerjarenprogramma ontwikkeling unt onderzoek SKB (proposal long-range program development and research $S K B$ ). Amsterdam: Foundation for Quality Improvement in Occupational Health Care (SKB), 1996. 